\title{
Herbert Ipser on his 65th Birthday
}

\author{
Hans Flandorfer • Adolf Mikula $\cdot$ Klaus W. Richter • \\ Peter Terzieff
}

Received: 29 June 2012/ Accepted: 5 July 2012

(C) Springer-Verlag 2012

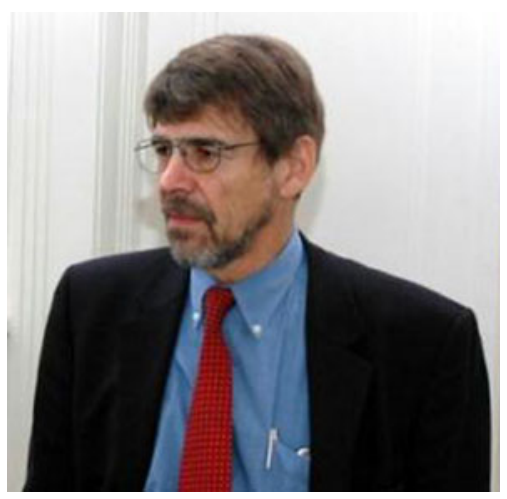

Herbert Ipser was born on September 22, 1947, in Vienna. After graduation from High School in 1966 he decided to study Chemistry at the University of Vienna. He started his thesis on the phase relationships and thermodynamics of the iron-tellurium alloy system under the guidance of K.L. Komarek and, in 1974, he received his $\mathrm{PhD}$ from the University of Vienna. In the same year, he was awarded a Fulbright grant which enabled him to spend the next two years as a post doctorate research fellow at the Department of Materials at the University of Wisconsin in Milwaukee, USA, in the group of Austin Chang. During his leave from Vienna, he worked on a book entitled "Phase Diagrams and Thermodynamic Properties of Ternary Copper-Metal Systems" which, since then, has become a valuable resource for materials scientists.

H. Flandorfer · A. Mikula $\cdot$ K. W. Richter $(\bowtie) \cdot$ P. Terzieff Department of Inorganic Chemistry/Materials Chemistry, University of Vienna, Währinger Strasse 42,

After his two-year stay in Milwaukee, Herbert Ipser returned to his home University in Vienna to resume his position as University Assistant in the Institute of Inorganic Chemistry. There he performed research in different fields of chemistry focussed on phase diagrams and on the thermodynamics of binary and multicomponent systems with emphasis on the close correlation with the underlying defect chemistry. In 1986 he successfully presented his habilitation treatise "Thermodynamics of NiAs-Phases". As Dozent for Inorganic Chemistry he steadily widened the range of his research activities into the field of materials science. During this period, a large number of scientific publications of a remarkable experimental standard appeared. Because of the widely acknowledged reliability of his experimental skills many of his findings found their way into common reference books. Finally, Herbert Ipser was designated Full Professor for Inorganic Chemistry at the University of Vienna in 1998.

In 2002 Herbert Ipser initiated the European project COST 531 on "Lead-Free Solder Materials". Under his accurate and strict guidance the project developed into one of the most successful actions, with the active participation of institutions from 21 different countries. As the Austrian representative of the succeeding project MP 0602 on "High Temperature Soft Solders" started in 2007, he was one of the most active supporters of the program.

Besides the initiation and the management of such projects, Herbert Ipser, with the help of his group, organized several scientific conferences in Vienna. Conferences on High Temperature Materials Chemistry (HTMC 94 and 06) and the Thermodynamics of Alloys (TOFA 88 and 04) held in Vienna were extremely successful in bringing people together working in the same fields. It was always his particular concern to keep the conference fee as low as possible and to support scientists who had problems obtaining travel grants to attend the conferences. In the years which followed, on 
account of the increasing demand for application-related materials, the Faculty of Chemistry recognized the need for more explicit representation of materials chemistry in the master curriculum. Finally, in 2004, the Institute of Inorganic Chemistry/Materials Chemistry was founded and Herbert Ipser was offered the chair of the new department.

In addition to his research activities, Herbert Ipser was always especially dedicated to teaching and working with students. He gave lectures in general, inorganic, and materials chemistry at all levels of university education and was responsible for the first semester general chemistry courses for almost 20 years. In this way, he introduced generations of students to the field of chemistry. He also contributed to the education of high-school teachers in chemistry and, last but not least, guided and advised dozens of master and doctoral students in their theses. Since the start of his career, one of his main concerns has been the quality of teaching and it was in recognition of his insistent endeavours for improvement that he became the Dean of Studies for the Faculty of Chemistry in 2008.

Herbert Ipser knows the importance of promoting and explaining the role of chemistry to the public and actively supports this objective by a variety of actions and initiatives, for example open house presentations and special events for school children. He is also active in the Austrian Chemical Society where he is currently president of the organization.

The laudation of Herbert Ipser would not be complete if we did not describe the person behind the scientist. Irrespective of his position, he always felt responsible for advancing the careers of his younger colleagues. In fact, many of them have also become successful in the field of chemistry. As a family man he loves his charming wife Sophia and his three children (Andreas, Christina, and Tina). He is persistent but has a soft temper, rarely raising his voice except when playing cards. He rides his bicycle, loves to swim, and plays basketball occasionally. Not too long ago he arrived at the institute on a Monday morning with a black eye. We all knew he had had a tough basketball game during the weekend.

It was a great pleasure for us to provide this short introductory note for the special issue of Chemical Monthly (Monatshefte für Chemie) on the occasion of the 65th birthday of Herbert Ipser. It contains several articles from his friends and colleagues all over the world and we sincerely thank them for their contributions. We would like to conclude this short tribute to Herbert Ipser with our personal best wishes for his future. 